\title{
EVOLUÇÃO DA CONOTAÇÃO POLÍTICA DOS ESTUDOS COMPARATIVOS EM EDUCAÇÃO
}

\author{
REJANE DE MEDEIROS CERVI \\ Doutor em Educação Comparada \\ Professor Adjunto do Departamento \\ de Planejamento e Administração \\ Escolar da UFPR
}

\section{RESUMO}

A autora formula uma via alternativa para definição da evolução dos estudos comparativos em educação a partir da consideração das razões institucionais pelas quais "se fez" comparação naquela área.

\section{ABSTRACT}

The author formulates an alternative definition of the evolution of comparative studies in education on the basis of the institutional reasons whereby comparison has been made in that field.

\section{INTRODUÇÃO}

A Educação Comparada é uma disciplina de extremo fascínio por inúmeras razões. Seu potencial analítico e crítico, a abrangência das realidades de observação, a vasta produção acadêmica e operacional, o caráter internacional e a recentividade de seu desenvolvimento epistemológico, entre outras características, dão margem a uma ampla gama de incursões. Sua justificativa se inicia, porém não 
se esgota, na ratificação do entendimento de que "é essencial reconhecer... não somente a existência de alteridade, mas a singular diversidade de nosso mundo"..

Há pouco mais de uma década, MARQUEZ (1972) publicou uma substanciosa obra onde introduziu uma visão integral da Educação Comparada, sistematizando as diferentes tendências ou correntes no que se refere à sua teoria e metodologia, ao mesmo tempo que delineou certas áreas resultantes das relações (da Educação Comparada) com outras disciplinas subsidiárias. ${ }^{2}$ Esta obra constitui a sistematização teórica de maior abrangência existente ainda nos dias de hoje. Outros estudos e publicações a sucederam, mas não chegaram a proporcionar a perspectiva consolidada dos conhecimentos acumulados nesta matéria. E tal se explica, porque a história da Educação Comparada está comumente abreviada em grande parte dos estudos de cunho genérico, embora muito se tenha escrito sobre os autores comparatistas e suas obras, em artigos avulsos.

Uma das vias mais empregadas para ordenar a Educação Comparada pauta-se em uma conduta empírica de classificação do que existe produzido e conhecido. Nesta linha, ROSSELLó (1963) inaugurou as propostas de estruturação da Educação Comparada, agrupando os trabalhos existentes segundo sua semelhança em termos de:

a) objeto da comparação (o que é comparado?);

b) área de comparação (qual a escala de observação? local? distrital? provincial? regional? nacional?);

c) natureza da comparação (compara-se descritiva ou explicativamente?)

d) ângulo da comparação (compara-se um momento determinado ou a evolução do desenvolvimento educacional?);

e) aplicabilidade (faz-se comparação pura ou aplicada?.$^{3}$

Ao lado desta via existem outras duas, segundo a classificação de MARQUEZ, que são a via histórica e a via ana- 
lítica. A via histórica busca precisar a natureza e o alcance da Educação Comparada, mediante o estudo seletivo das obras clássicas mais significativas a partir do que provê o reconhecimento de questões, tais como, temas abordados, problemas considerados, métodos e disciplinas subsidiárias utilizadas. FUENTEALBA HERNANDEZ (1963) ${ }^{4}$ apresentou um estudo básico neste sentido.

A via analítica supõe a delimitação arbitrária dos estudos comparativos por campos disciplinares. Contudo, pelo fato de possuir (a Educação Comparada) características indiscutíveis de transdisciplinaridade, "resulta difícil determinar quando um enfoque antropológico, econômico ou sociológico, de um problema, se situa no campo específico dessas disciplinas ou passa a pertencer ao campo da Educação Comparada. A abordagem analítica nos conduz ao difícil problema da relação entre a Educação Comparada e as ciências afins e auxiliares". ${ }^{5}$ Por exemplo, quando se estuda um problema educacional em forma comparada com o auxílio da economia - tal como a despesa pública com a educação - indaga MAROUEZ, encontramo-nos no campo da economia ou no campo da Educação Comparada?

Mas MARQUEZ não avaliou a variante analítica, aliás bem sucedida, que ele mesmo haveria de adaptar para situar o nível de complexidade científica dos estudos comparativos. A partir da discussão do conceito de ciência de vários autores, ele concluiu que:

a) é possível, para a metodologia comparativa, conciliar determinados aspectos com a investigação científica;

b) esta possibilidade evoluiu no tempo, e a sua reflexão serve para subsidiar a definição de etapas históricas no desenvolvimento da Educação Comparada.

Desta forma, este Autor relaciona os principais enfoques metodológicos com as etapas históricas da Educação Comparada, conforme se vê no Quadro I. 
Quadro I - Etapas históricas no desenvolvimento da Educação Comparada. Principais representantes e enfoques metodológicos. ${ }^{6}$

ETAPA DESCRITIVA: JULLIEN, ARNOLD, MANN, SARMIENTO, COUSIN.

ETAPA EXPLICATIVA (viés histórico, modelo teórico evolutivo):

SADLER (transição entre a primeira e a segunda etapa);

KANDEL, ULICH (enfoque histórico);

HANS (enfoque funcional, baseado no background histórico);

LAUWERYS, HESSEN (enfoque filosófico);

SCHNEIDER, MOEHLMAN (enfoque antropológiCo).

ETAPA COMPARATIVA, PREDITIVA (viés sociológico, modelo estrutural-funcional):

ROSSELLÓ (enfoque preditivo via justaposição); BEREDAY, HOLMES (enfoque de problemas, comparação pp. dita)

KAZAMIÁS (enfoque funcional, comparação pp. dita);

ANDERSON (enfoque tipológico, comparação pp. dita);

FERNIG (enfoque global, comparação pp. dita).

Nossa preocupação com uma via alternativa explicativa da evolução dos estudos comparativos, baseada na consideração do uso social dos resultados desta disciplina, não exclui e não invalida os ensaios apresentados fundamentados na redução acadêmica da Educação Comparada (ver quadro II). Antes nossa hipótese de trabalho está apoiada nos seguintes pressupostos:

$10^{\circ}$ - que a Educação Comparada desenvolveu-se, básica e simultaneamente, ainda que em diferente ritmo e direção, nas instituições acadêmicas (particularmente as universidades) e nas organizações internacionais; 
2. - que a Educação Comparada desenvolvida nas organizações internacionais é expressão direta de uma consistente prática de intercâmbio nessa escala;

$3^{\circ}$ - que o intercâmbio educacional internacional, ainda que calcado numa inspiração expansionista, ${ }^{7}$ apresentou facetas motivacionais divergentes, fazendo com que a Educação Comparada se desenvolvesse com enfoques diferenciados;

4. - que cabe considerar o papel de "mediação" dos estudos comparativos nesse intercâmbio internacional ainda que quase sempre desempenhado de forma implícita.

Quadro II - Vias de ordenação dos estudos comparativos em educação.

Procedimento

Critério

Autores

Representativos

Procedimento em- Classificação da pro- ROSSELLÓ pírico. dução existente co- (1963) nhecida.

Procedimento his- Estudo seletivo das FUENTEALBAtórico ortodoxo. obras clássicas. HERNANDEZ

(1963)

Procedimento ana- Estudo seletivo dos KNELLER lítico sobre a cono- conteúdos em função (1963) tação científica. do tratamento acadê- MARQUEZ mico (enfoques meto- (1972) dológicos).

Procedimento ana- Estudo seletivo dos NOSSA lítico sobre a cono- conteúdos em função PROPOSTA tação política. do uso social (políti- (1981)

co) dos seus resultados. 
Considerados os pressupostos aqui enunciados, nossa questão problemática central se volta à relação entre a evolução dos estudos comparativos e as razões de ordem institucional pelas quais "se fez" comparação na área da educação.

A operacionalização da questão central, em termos gerais, pretende demonstrar que

seja qual for a natureza teórica dos estudos comparativos descritiva, interpretativa, preditiva ou de contextualização ou comparação propriamente dita - haverá sempre um uso social potencial, diferenciado, correspondente. Uma dada condição teórica serve a uma intenção política determinada e vice-versa. As próprias organizações não acadêmicas, por isso mesmo, já produziram teoria comparativa na área da educação. ${ }^{8}$

\section{DESENVOLVIMENTO}

Entendemos que a evolução da conotação política da Educação Comparada pode ser reconhecida pela indicação de nuanças intencionais no uso social dos estudos comparativos. Assim sendo, o marco político inicial do uso social dos estudos comparativos estaria vinculado à constatação da manifestação de superação do caráter de observação pessoal diletante pela intenção política de aproveitamento dos seus resultados.

Esta intenção política de aproveitamento da comparação sistemática em educação, ocorrida a nível institucional e particularmente detectável no quadro das organizações não acadêmicas, desenvolveu-se em duas esferas que se superpuseram no tempo, as quais estão relacionadas, por sua vez, a um movimento de ordenação nacional, de um lado, e a um movimento de ordenação mundial, de outro. (Ver quadro III). 


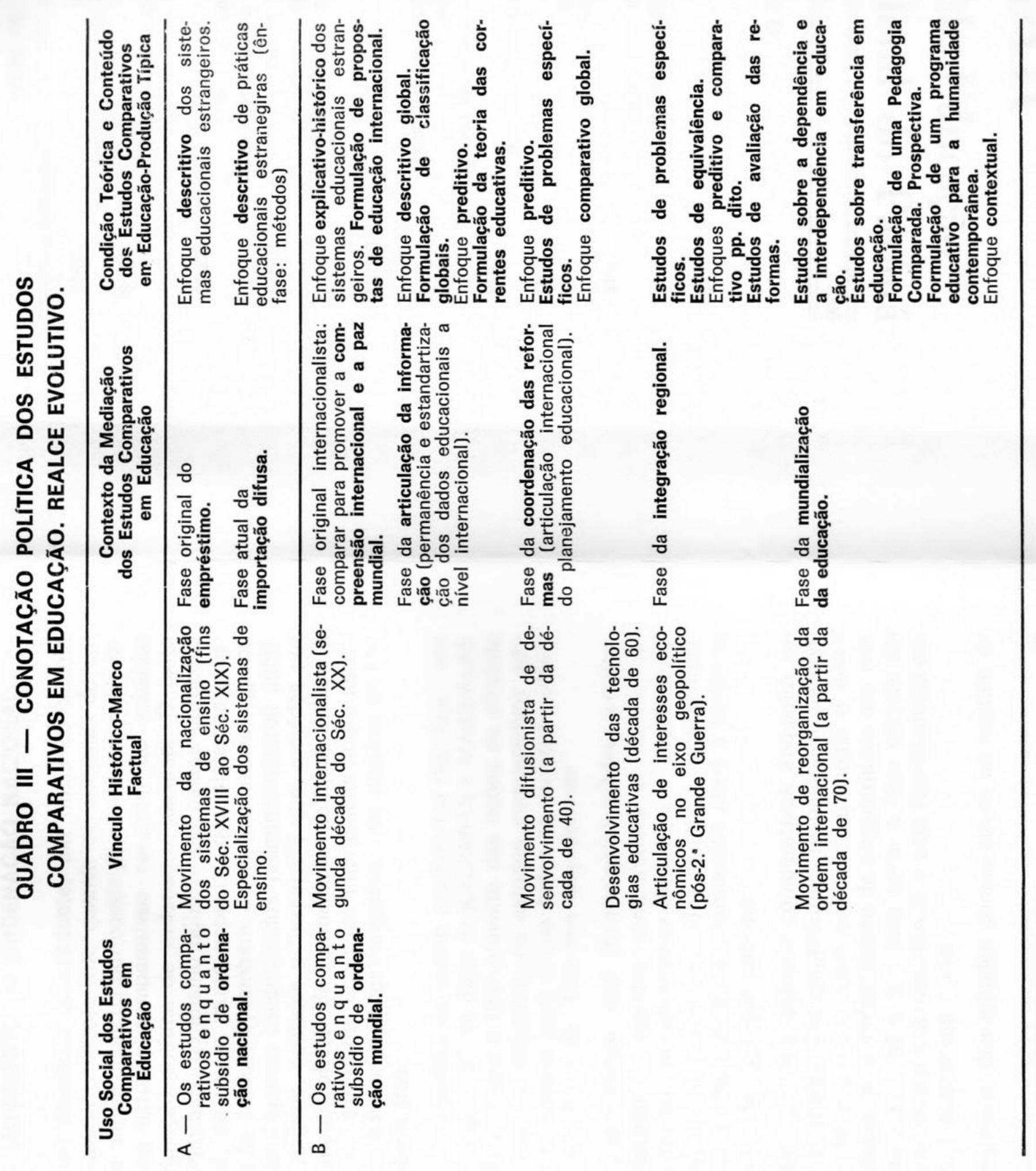




\section{A - MOVIMENTO DE ORDENAÇÃO NACIONAL.}

Em um momento antecedente, em finais do século XVill e durante o século XIX, quando os sistemas de ensino se tornaram públicos por contingência de sua nacionalização, os estudos comparativos serviram de subsídio a uma intenção política de ordenação nacional. O êxito da sistematização do ensino público nos países europeus ocidentais, de forma muito especial, dos sistemas prussiano, inglês, francês e, também, do norte-americano, gerou o fluxo de viajantes credenciados (administradores públicos, professores, políticos e "experts") que, movidos por um sentimento oficial de curiosidade política, tinham a seu mister a tarefa de reproduzir impressões sobre as organizações educacionais estrangeiras e de decifrar as fórmulas reformistas.

Este intercâmbio de cunho assimétrico deu lugar aos estudos "elogiosos", no dizer de KAZAMIAS e MASSIALAS (1968) (9). Voltados a tirar proveito das lições de eficácia dos sistemas estrangeiros, os estudos comparativos serviram de referência para o que todos os autores concordam em denominar de "fase dos empréstimos".

Em uma subfase, que chamaríamos subfase original do empréstimo, os estudos comparativos se caracterizaram pela feição eminentemente descritiva e pouco sistemática bem como pelos conteúdos seletivos apologéticos, com vistas a uma coleta de informações úteis à melhoria e à mudança da educação nacional.

A utilização dos estudios comparativos enquanto recurso de mediação dos empréstimos respaldou-se na consideração da educação como entidade autônoma e numa total ausência de reconhecimento da singularidade das realidades nacionais. Mas, em todo caso, a fase original do empréstimo teve a sua importância e está representada em inúmeras e sugestivas obras ${ }^{10}$.

O uso social dos estudos comparativos no sentido da 
ordenação nacional superou a subfase original dos empréstimos (que, aliás, se estendeu até a segunda década do século $X X$ ), mas se manteve de forma cada vez mais difusa ao longo dos tempos. Tal afirmação pode ser verificada pelo estudo das inovações. As inovações educacionais não refletem de todo, ainda nos nossos dias, um processo de formulação endógena. A importação, o transplante de soluções educacionais, constituem prática generalizada e, até agora, não controlada e nem criticada suficientemente ${ }^{11}$.

Não é difícil comprovar que os estudos comparativos, embora dispondo de uma condição metodológica complexa que permite a explicação das soluções educacionais em função de seus contextos, não subsidiam o circuito da decisão política neste sentido. Pelo contrário, os estudos comparativos têm se prestado a reforçar a imitação das propostas de reformas educacionais estrangeiras com o auxílio da força de demonstração das abordagens de teor descritivo. O enfoque descritivo exclusivo tem impedido a mediação crítica nos processos de adoção de inovações nos sistemas educacionais ${ }^{12}$.

\section{B - MOVIMENTO DE ORDENAÇÃO MUNDIAL.}

A nossa contemporaneidade é expressão de um intenso e denso intercâmbio na área da educação. Este intercâmbio se faz tanto de forma personalizada como de forma institucionalizada, interessando, esta última, à nossa interpretação da evolução da conotação política dos estudos comparativos, pois é com o surgimento das instituições internacionais com competência especializada na área da educação que processos singulares de intercâmbio passam a desempenhar uma base instrumental definitiva para a adoção de políticas e práticas educacionais nacionais.

Neste movimento de ordenação mundial é possível identificar nuanças intencionais desde uma postura internacionalista, cujo marco está relacionado à instalação da 
Comissão de Cooperação Intelectual (1921) e à criação do Bureau Internacional de Educação (1925), este último por injunção do Conselho Diretivo do Instituto Jean-Jacques Rousseau, em Genebra ${ }^{13}$, até uma intenção de mundialização da educação ${ }^{14}$.

Ao nos referirmos à postura internacionalista, queremos dizer que os estudos comparativos em educação foram enriquecidos, desde os seus primórdios, pelo incentivo dos mecanismos de interdependência e solidariedade, os quais foram, por sua vez, instituídos sobre uma base moral apoiada na aceitação de uma vocação universal da cultura e no desejo coletivo de uma paz mundial. Essas aspirações culminaram com a criação da Organização das Nações Unidas para a Educação, a Ciência e a Cultura - UNESCO - em 1945, cuja função se afirmou no sentido de favorecer a produção e reprodução de propostas cada vez mais concretas sobre uma educação internacional.

No quadro de atuação da UNESCO, as Conferências Internacionais de Instrução Pública constituíram o principal forum para a institucionalização de certos padrões educacionais universais produzidos pelos estudos comparati$\operatorname{vos}^{15}$.

Provindo desse meio internacional, Leo FERNIG (1959) apresentou uma proposta teórica de comparação global. Seu enfoque pressupõe a elaboração de normas internacionais mais científicas que serviriam de pautas preliminares para efeito comparativo. $\mathrm{O}$ estudo de qualquer sistema educacional em particular pode ser feito, então, a partir da desnacionalização do marco de referência comumente utilizado nos estudos comparados, o que possibilitaria uma visão do mundo como totalidade, comprometida com um substrato normativo internacional ${ }^{16}$.

Os estudos comparativos ganharam impulso, também e ainda, a partir de outra nuança intencional adstrita ao movimento de ordenação mundial, que, sem se opor à inspiração internacionalista, ganhou autonomia pela sua 
condição técnica. Tal nuança correspondeu aos esforços empenhados no estabelecimento de um mecanismo de informação permanente sobre os sistemas educacionais nacionais. O Bureau Internacional de Educação - BIE - foi, desde sua origem, o órgão centralizador desta tarefa. Com sua integração à UNESCO (sancionada apenas em 1968, embora tenha sido ensaiada a partir de um acordo formado em 1952 para favorecer "u'a maior unidade de ação" entre as duas organizações e efetivada, finalmente, em razão de impasses de ordem financeira, político-jurídica e pedagógico-científica, ${ }^{17}$ os dados educacionais alcançaram uma estandartização definitiva.

A articulação das informações de todos os sistemas educacionais das nações filiadas à UNESCO consolidaram uma visão descritiva mundial da educação, a qual foi trabalhada preliminarmente por ROSSELLÓ, gerando sua proposição acerca da teoria das correntes educativas ${ }^{18}$. A justaposição, enquanto fase metodológica comparativa, promoveu a emergência do enfoque preditivo, representado por aquele autor e por outros atuais que crêem que a evolução dos sistemas educacionais, hoje, "é determinada mais pelas tentativas de previsão de como será o futuro, que pelas forças do passado" ${ }^{19}$. A principal mostra desta literatura educacional comparativa está editada pela UNESCO ("L'Education dans le monde", "Annuaire de l'éducation", "Études et documents" e outras publicações), OCDE e outras organizações internacionais, algumas delas não necessariamente especializadas em educação.

Entretanto, a informação permanente e a sua estandartização viabilizaram uma intenção subseqüente de coordenação do planejamento educacional e de promoção massiva da educação em escala mundial. Os estudos comparativos realizados pelas organizações internacionais passam a alimentar uma estratégia difusionista emergente na década de 40, no período pós-guerra. Essas organizações, com vínculo governamental ou não, vêm negociando, então, modelos educacionais ocidentais alternativos, os quais 
vêm evoluindo desde uma postura radical de difusionismo de desenvolvimento (enfatizada na década de $60 \mathrm{com}$ o lançamento dos grandes projetos sobre utilização de tecnologias educativas e a divulgação de paradigmas reformistas) até a reação a essa postura, manifestada no final da mesma década, quando o Instituto Internacional de Planejamento Educacional - IIPE - da UNESCO, vem de adotar uma discussão sobre modelos de desenvolvimento endógeno. Esta discusão colocou em questão as dimensões sociais, endógenas e culturais dos programas educativos, argumentando pelo reconhecimento das condições de singularidade das realidades nacionais. As reflexões aí incorporadas contribuíram, sem dúvida alguma, para o crescimento crítico dos estudos comparados. Os debates desenvolvidos no seio da Sociedade Européia de Educação Comparada são altamente representativos desta vertente analítica.

A coordenação do planejamento educacional tomou feição de circunstância mais restrita em termos geopolíticos quando interesses de caráter essencialmente econômico e espacialmente limitados condicionaram o redirecionamento das propostas e estudos políticos na área da educação. $\mathrm{O}$ atendimento à maior identidade (ou articulação?) de interesses e a busca de consenso sobre ações cooperativas fizeram, da inťegração regional, uma estratégia política de maior efeito sobre o controle social e, por ende, sobre a educação. A implementação dos escritórios regionais da UNESCO e a periodicidade das conferências regionais dos Ministros de Educação, destacáveis desde a década de 60 , assim como os serviços de documentação e informação educativa, ilustram aquele direcionamento.

Na Europa, as ações de cunho integrativo regional não só se deram de forma mais explícita como lograram resultados mais concretos. Sob a égide do Conselho de Ministros da Comunidade Econômica Européia, por exemplo, em 1963, ficou estabelecido um "decálogo de princípios gerais" que serviu de base orientativa a uma política de 
formação profissional com vistas à polivalência das estruturas formativas vigentes nos distintos países integrantes daquela comunidade. São inúmeros os estudos voltados ao ensino europeu, e, no acervo da Educação Comparada, a formação profissional e a avaliação das políticas nacionais de educação (reformas) têm especial relevo.

No continente americano, para situarmos a nossa realidade regional, o trabalho da Organização dos Estados Americanos - OEA - foi bastante mais implícito em matéria de mediação analítica pela comparação no campo da educação. Um estudo sobre a ideologia dominante nesta Organização, em todos os tempos, pode revelar menos um empenho de afirmação pan-americanista (o motivo essencial de sua institucionalização) e mais um recurso de sustentação da hegemonia norte-americana. Tal comportamento impediu, indiretamente, ou pouco estimulou, a Educação Comparada no sentido de sua complexificação teórica e vocação política, ao contrário do que sucedeu nas organizações internacionais que atuaram no continente europeu. Tal entendimento, todavia, não é compartido por alguns autores brasileiros, que apregoam a relevância do trabalho da OEA para os estudos comparativos. É preciso, no entanto, situar as diferentes percepções. Muito embora possamos reconhecer a intensidade das ações e estudos da OEA no campo do planejamento e da administração da educação, especialmente sensível nas últimas duas décadas; muito embora possamos afiançar a competência dos intelectuais que lideraram a programática cultural e educacional daquele organismo - tais como os brasileiros Alceu de Amoroso Lima, Érico Veríssimo e Viana Moog, entre ilustres latino-americanos - em épocas mais remotas; muito embora tenhamos que considerar a atuação conjunta com outros órgãos, inclusive com a UNESCO, entendemos que os estudos comparativos, nessa instância, não ultrapassaram o feitio descritivo e difusionista internacional, não atingindo, desta forma, um grau de criticidade contextual requerida. Verifique-se, para exemplo, o estudo da Oficina Regional de Educação da UNESCO para a América Latina 
e o Caribe sobre a "evolução recente da educação na América Latina" (1974).

Por fim, a potencialidade de utilização dos estudos comparativos está, na atualidade, estreitamente vinculada ao movimento de mundialização da educação. $O$ discurso sobre a ordem internacional e, presentemente, sobre a reorganização dessa ordem - uma nova ordem internacional - estruturada sobre uma dinâmica de conciliação e reconhecimento mútuo entre as nações, compromete a Educação Comparada nos termos expressos por SUCHODOLSKI (1981). Este autor acentua o interesse dos estudos comparativos em sua dimensão internacional e no intuito de prover as diretrizes para um programa educativo para a humanidade contemporânea resultante da consideração da condição de responsabilidade das nações pelo futuro do mundo ${ }^{20}$.

Associam-se ao movimento da mundialização da educação, ainda, os conteúdos da Educação Comparada centrados na teoria da dependência, no estudo da transferência educacional e as propostas subsidiadas pelo pensamento utópico que passam a condicionar as estratégias educacionais contemporâneas ao devir de uma nova ordem internacional. Essas propostas, entretanto constituem matéria ética que não pode sofrer analogia com a "futurologia educacional", o produto extrapolado do enfoque preditivo ${ }^{21}$.

\section{PRIMEIRAS CONCLUSÕES SOBRE A QUESTÃO CENTRAL DESTE ESTUDO}

(a) A identificação de uma evolução de conotação política no desenvolvimento dos estudos comparativos, enquanto possibilidade teórica:

1. - é viável pela detecção de regularidades intencionais ocorridas no processo de intercâmbio internacional e traduzidas nas posições teóricas, nos programas e nos estudos respectivos das instituições nesta esfera internacional; 
2. ${ }^{\circ}$ - não exclui outros estudos de determinação evolutiva baseados em quaisquer critérios. Antes, busca recuperar o nexo entre a produção teórica e a mediação operacional - política dos estudos comparativos;

3. - desenvolveu-se, basicamente, pela emergência de um campo institucional internacional que regulou as relações de intercâmbio na área da educação, inclusive pela produção e propagação de representações educacionais dentro de progressivos "estilos internacionais";

4. - transcende as preocupações anteriores sobre (a) o que existe em Educação Comparada ("é tudo o que os comparatistas fazem") e (b) a viabilidade da comparação (como interpretar as diferenças, como fazer a comparação?), com o fito de prover a revisão do sentido (político) da Educação Comparada (por que fazer comparação nas instituições?);

5. - ratifica, de forma conclusiva, a dimensão internacional dos estudos comparativos enquanto contexto compulsório das decisões políticas a nível nacional.

b) A explicação do nexo entre conteúdos, condição teórica e a função de mediação política dos estudos comparativos, evidencia, entre outras, as seguintes regularidades:

6. - relação entre o enfoque descritivo dos sistemas educacionais estrangeiros e a fase "original" do empréstimo, nos estudos voltados à ordenação nacional;

7. - relação entre o enfoque descritivo de práticas educacionais estrangeiras e a fase atual de importação difusa de modelos, metodologias e tecnologias, nos estudos voltados à ordenação nacional; 
8. - relação entre o enfoque explicativo-histórico e a formulação de propostas de educação internacional com a fase internacionalista, voltada à compreensão internacional e à paz mundial;

$9 .^{\circ}$ - relação entre o enfoque descritivo global (formulação de classificações globais) e o enfoque preditivo (formulação da teoria das correntes) com a fase de articulação da informação, voltada à permanência e estandartização dos dados educacionais internacionais;

$10 .^{\circ}$ - relação entre os enfoques preditivo e comparativo global com a fase da coordenação das reformas, voltada à articulação internacional do planejamento educacional;

$11 .^{\circ}$ - relação entre os enfoques preditivo e comparativo propriamente dito (estudos de problemas específicos, estudos de equivalência e estudos de avaliação das reformas) com a fase da integração geopolítica regional;

$12 .^{\circ}$ - por fim, relação entre os enfoques contextual e prospectivo (estudos sobre dependência e interdependência, transferência em educação, formulação de um "programa educacional para a humanidade contemporânea") com a fase de mundialização da educação.

\section{REFERENCIAS BIBLIOGRÁFICAS}

(1) FURTER, P. Os sistemas de formação em seus contextos. Introtrodução a um método de educação comparada. Rio de Janeiro, Editora da Fundação Getúlio Vargas, 1982 : VI

(2) MARQUEZ, A.D. Educación Comparada. Teoría y metodología. Buenos Aires, Librería El Ateneo Editorial, 1972, 622 pgs.

(3) ROSSELLÓ, P. "Concerning the Structure of Comparative Education". IN Comparative Education Review. New York, Teachers College, Columbia University, vol. VII, (2), oct. 1963: 13 e segs. 
(4) FUENTEALBA HERNANDEZ, L. "Le concept d'Éducation Comparér". IN International Review of Education. Vol. 8, (3-4), 1963:363 e segs.

(5) MARQUEZ, op. cit., 16.

(6) Adaptado de MARQUEZ, op. cit., 119-120.

(7) A tese do expansionismo como condicionante do intercâmbio internacional na área da educação está desenvolvida em MEDEIROS CERVI, R. La perspectiva internacional en el area de la educación. Barcelona, Universidade Central de Barcelona, 1981 (Tesis doctoral).

(8) MEDEIROS CERVI, R. A contribuição da Educação Comparada para os estudos de atualização da formação do educador brasileiro. Brasíila, II Seminário Nacional de Educação Comparada, promovido pela Sociedade Brasileira de Educação Comparada, 1984 (Conferência).

(9) KAZAMIAS, A.M. e MASSIALAS, B.G. Tradición y cambio en la educación. México, UTEHA, 1968:3-4.

(10) 1795 F.A. HECHT (alemão): "De re scholastica Anglica cum germanica comparada"; 1802, C.A. BASSET (francês): "Ensaio sobre a educação e a organização de alguns setores da instrução pública"; 1814, G. CUVIER (francês): "Relatórios sobre a instrução pública na Alemanha, na Holanda e na Itália"; 1812 - 1817, Marc-Antoine JULLIEN (francês): Vários estudos sobre a organização da educação montessoriana na Suiça. "Esboço de uma obra sobre a Pedagogia Comparada"; 1815, John CRISCOM (americano); "Relatório sobre a instrução européia na Inglaterra, França, Suiça, Itália e Holanda"; 1818, FERRER y CASAUS (espanhol): "Sistema inglês de instrução ou coleção completa das invenções e melhorias postas em prática nas escolas da Inglaterra"; 1824, A.H. NIEMEYER (alemão): "Observações de viagens na Alemanha e no estrangeiro, com lembranças memoráveis da vida e dos contemporâneos no decurso dos 50 últimos anos"; 1827, E.G. FISHER (alemão): "Estudo comparado entre os estabelecimentos escolares da Alemanha e da Inglaterra"; 1832 a 1837, V. COUSIN (francês): "Relatório sobre o estado da instrução na Alemanha e particularmente na Prússia" (1832). "Estado da instrução secundária no reino da Prússia" (1834). "Memória sobre a instrução superior na Prússia" (1837); 1832 1836, E. A. KRUSE (alemão): Réplica ao relatório de V. COUSIN (1832). "Considerações sobre os estabelecimentos 
escolares na Inglaterra" (1836); 1838, C.E. STOWE (americano): "Relatório sobre a instrução elementar pública na Europa"; 1837 - 1848, H. MANN (americano) (o iniciador do ensino público gratuito e obrigatório nos Estados Unidos); Relatórios anuais sobre a educação na Europa. Observações sobre a aplicação do método Pestalozzi nas escolas alemãs; 1838, F.W. THIERSCH (alemão): O estado do ensino público na Alemanha, na Holanda, na França e na Bélgica; 1838, E. DECPETIAUX (belga): "Do estado da instrução primária e popular na Bélgica, comparada com o da instrução na Alemanha, na Prússia, na Suiça, na França, na Holanda e nos Estados Unidos"; 1839, A.D. BACHE (americano): Relatório sobre a educação na Europa para os Trustees do Girard College para Órfãos; 1940, Pedro Felipe MONLAU (espanhol): "Da instrução pública na França. Ensaio sobre seu estado em 1938 e 1939; 1840 Melchor SANCHEZ TOCA (espanhol): "Memória sobre o plano de estudos, a organização e o pessoal das escolas médicas estrangeiras"; 1840, W.E. HICKSON (inglês): "Escolas holandesas e alemãs"; 1841, Manuel Benito AGUIRRE (espanhol): "Esquema histórico, filosófico e político do estado da educação primária na Espanha comparada com o de outros países da Europa"; 1843, Horace MANN (americano): "VII Relatório-subsídio sobre o conceito de ensino público"; 1841-1843, E. RENDU (francês): "Relatório sobre a educação popular na Alemanha do Norte"; 1847, Matthew ARNOLD (inglês): Relatórios editados entre 1860-1865 sobre o ensino na França e na Alemanha; 1847, J. M. BADOUIN (francês): "O ensino primário e especial na Alemanha"; 1854-1872, H. BARNARD (americano): "Educação nacional na Europa" (1854). "Educação nacional, sistemas instituições e estatísticas da instrução pública em diferentes países" (1872); 1857 - 1861, L. TOLSTOI (russo): "Escritos pedagógicos" (educação na Europa); 1863, K. D. OUCHINSKI (russo): Vários relatórios sobre a educação na Alemanha Suiça, França e Bélgica; 1865, M. ARNOLD (inglês): Relatórios sobre o ensino secundário na França, Alemanha, Itália e Suiça; 1867, J. FRASER (inglês): "Relatório sobre sistema escolar comum dos Estados Unidos e do Canadá"; 1865, J. M. BAUDOUIN (francês): "Relatório sobre o estado atual do ensino especial e do ensino especial e do ensino 
primário na Bélgica, na Alemanha e na Suiça"; 1868, Ministério da Instrução Pública da França: Sondagem sobre o ensino secundário na Europa; 1868, L. STEIN (alemão): Relatório sobre a educação elementar pública na Alemanha, Inglaterra e outros países; 1869, Célestin HIPPEAU (francês): "A instrução pública nos Estados Unidos". "A instrução pública na Inglaterra" (1970). (Segundo LOURENÇO FILHO, estes dois trabalhos foram traduzidos e publicados pelo Diário Oficial do Brasil, e depois reunidos em volumes impressos pela Tipografia Nacional, como então se chamava a Imprensa Oficial, entre 1871 e 1874, 1869, Francisco Javier COBOS (espanhol): "Estudos críticos históricos e administrativos sobre a parte pedagógica da Exposição Universal celebrada em Paris em 1867"; 1869, Joaquim FERREIRA MACEDO (brasileiro): "A instrução pública na Rússia"; 1874, D. CAMPBELL (inglês): "Educação mista de meninos e meninas na Inglaterra e na América"; 1874, A. MOLNAR: "Estudos pedagógicos na Suiça e na Baviera"; 1877, Nicolás DIAZ Y PEREZ (espanhol): "cifras do ensino na Europa e nos Estados Unidos da América"; 1878, Aisclo FERNANDEZ VALLIN Y BUSTILLI (espanhol): "A instrução popular na Europa"; 1878, F. BUISSON (francês): "Relatório sobre a instrução primária na Exposição Universal de Filadélfia em 1876"; 1878, C. HIPPEAU (francês): "A instrução pública na Rússia". "A instrução pública na América do Sul"; 1879, Gustavo BAGGE (francês): "Tabelas estatísticas dos diversos países do univeiso para os anos 1877"; 1879, Pedro de ALCÂNTARA Y GARCIA (espanhol): "Resumo do estado da educação popular na Espanha, comparando-se com o alcançado nas demais nações da Europa"; 1880, Manuel Bartolomé COSSIO (espanhol): "O Congresso Internacional em Bruxelas"; 1882 - 1883, Rui BARBOSA (brasileiro): Pareceres sobre o ensino primário, secundário e superior; 1883, M. C. LANDREYT (francês): "A instrução pública na França e as escolas americanas"; 1882 - 1897, E. DREYFUS-BRISSAC (francês): "A educação nova; estudos de pedagogia comparada"; 1884, Bureau of Education-Washington: "Estatística do ensino elementar em cinqüenta dos países mais importantes"; 1884, E. JOURDAN e G. DUMONT (franceses): "Estudo sobre as escolas de comércio na Alemanha, na Austria-Hungria, 
na Bélgica, na Dinamarca, na Itália, na Rumania, na Rússia, na Suécia, na Suiça e nos Estados Unidos da América"; 1886, R. LAISHLEY (néo-zelandês): "Relatório sobre o estado da educação na Grã-Bretanha, França, Suiça, Itália, Alemanha, Bélgica e Estados Unidos"; 1886, Ricardo RUBIO (espanhol): "A instrução pública em Portugal". "O ensino primário e profissional em Paris"; 1886, M. B. COSSIO (espanhol): "Situação da educação pública na Bélgica"; 1887, R. Esteban SAN JOSE (espanhol): "Resumo das instituições de ensino mercantil na Europa"; 1889, A. SONNENSCHEIN (inglês): "Códigos educacionais nos países estrangeiros"; 188, D. MURRAY (americano): "O uso e o abuso dos exames com esquemas usados hoje na China, França, Alemanha e Inglaterra"; 1889, L. R. KLEMM (americano): "Escolas européias"; 1890, H. LANGE (americano): "Educação superior da mulher na Europa"; 1891, G. W. ROSS (canadense): "Relatório sobre a educação compulsória no Canadá, GrãBretanha, Alemanha e Estados Unidos"; 1983, Mianuel José Suiça, Suécia, Bélgica, Inglaterra e França"; 1895, L. DERIE (belga): "A escola e o Estado: ensaio de legislações comparadas"; 1896, L. SEELEY (americano): O sistema escolar comum da Alemanha e sua lição para a América"; 1896, Leopoldina Tavares PORTO CARRERO (brasileira): "O ensino público primário na França, Espanha e Portugal"; 1897, P. E. LEVASSEUR (francês): "O ensino primário nos países civilizados"; 1898, BOARD OF EDUCATION OF LONDON: Relatórios especiais sobre a educação; 1899, Angel SALCEDO Y RUIZ (espanhol): "O ensino secundário na Espanha e fora da Espanha"; 1899, Ch. H. THURBER (americano): "Princípios de organização escolar: um estudo comparativo sobre os sistemas dos Estados Unidos, Inglaterra, Alemanha e França"; 1900, M. E. SADLER (inglês): Inquéritos especiais e relatórios sobre a educação na Europa e Estados Unidos; 1901, R. E. HUGHES (inglês): "Escolas em casa e no estrangeiro"; 1911, J. BROWN (americano): "A formação de professores para as escolas secundárias"; 1912, A. FLEXNER (americano): "A educação médica na Europa"; 1913, C. BRERETON (inglês): "Estudos sobre a educação estrangeira".

(11) A este respeito, ver MEDEIROS CERVI, R. A inovação por transferência enquanto unidade de estudo da Educação Com- 
parada. Comunicação apresentada ao Seminário de Inovação em Educação, Curitiba, Coordenação dos Cursos de Pós-Graduação em Educação da UFPR e Associação Brasileira de Tecnologia Educacional/PR., dezembro 1984. Idem. "Transferência em educação" In Em Aberto. Brasília, MEC, ano 3, n. 24, nov./dez. 1984:19-23.

(12) A ausência da mediação crítica dos estudos comparativos no Brasil tem relação direta com a normatização pedagógica adotada pelo Conselho Federal de Educação. Desde 1962, pelo Parecer 251, aquele colegiado superior inverteu a significância da Disciplina de Educação Comparada nos currículos de Pedagogia, atitude que foi ratificada pelos Pareceres 252/69 e $632 / 69$ que fixaram o currículo mínimo de Pedagogia e o conteúdo específico da Faculdade de Educação, respectivamente. A prática da comparação tem sido, pois, privilégio exclusivo do legislador, em função do seu gosto e ideologia particulares.

(13) ROLLERS, S. "Les origines du Bureau International d'Éducation". In Le Bureau International d'Éducation au service du mouvement éducatif. Paris, UNESCO, 1979:35-48.

(14) MEDEIROS CERVI, R., op. cit.: 93-115.

(15) Evidentemente, a UNESCO diversificou as suas estratégias até uma cooperação técnica e financeira. As Conferências Internacionais de Educação se mantêm, porém, com a mesma importância.

(16) FERNIG, L. "El enfoque global en la educación comparada". In MARQUEZ, op. cit.: 295-305.

(17) EGGER, E. "L'intégration du BIE à I'UNESCO". In le Bureau International. .. op. cit.: 107-118.

(18) ROSSELLO, P. Teoría de las corrientes educativas. Barcelona, Promoción Cultural, 1978.

(19) VEXLIARD, A. Pedadogia Comparada. São Paulo, Editora Nacional e Editora da USP, 1970.

(20) SUCHODOLSKI, B. "L'Éducation Comparée: porquoi faire?". In Les sciences de l'education: perspectives et bilans européens. In CAVICCHI-BROQUET, I et FURTER, P. (Ed.). Genève, Cahiers de la Section des Sciences de l'ÉducationPratiques et Théorie, n. ${ }^{\circ}$ 23, 1982:97-105.

(21) A literatura que ilustra a Educação Comparada Prospectiva vem adensando de 1970 para cá. Ver LÊ THAN KHOI, "Note sur l'education et le nouvel ordre". In Education Comparée, Sèvres, CESE, 1980. 